\title{
A new curriculum for a new public school Terry Wrigley
}

\author{
Abstract \\ This article is written in response to widespread concerns about the inadequacy of the school \\ curriculum in England, and the urgent need to rethink what public education should involve. \\ It builds on earlier contributions in FORUM and elsewhere by discussing curricular \\ opportunities arising from Labour's proposal for a National Education Service. This is \\ particularly timely given the limited horizons and understanding shown in Ofsted's call for \\ better curriculum planning. \\ In contrast to neoliberal obsessions with schooling as the production of human resources, and \\ the neoconservative dependence on tradition, the article discusses how we might build a \\ curriculum oriented to social justice, environmental responsibility and democratic \\ citizenship. It addresses core issues such as age appropriateness; the relationship between \\ everyday and academic knowledge; the importance of cognitive, practical, aesthetic and \\ ethical dimensions; and how we might make a socially just and politically serious selection of \\ knowledge. Whilst drawing on the strengths of earlier curriculum development, particularly \\ in the 1960s and 1970s, it also points towards more recent international developments \\ drawing on place, story and enquiry, which have been eclipsed by high-stakes acccountability \\ regimes. This broad ranging article throws out a challenge: how to avoid retreading a \\ traditional path of alienated knowledge acquisition and create a framework for authentic \\ learning and really powerful knowledge.
}




\section{Educational aims and curricular orientations}

There is widespread discontent with the English school curriculum, from various perspectives. The current (Gove) version of the National Curriculum is singularly lacking in overall aims whilst being overloaded with technical detail. At primary level in particular it consists of two and a half subjects (Mathematics, Science and those parts of English related to literacy). Further distortion occurs at school level due to the pressures of high-stakes accountability - a problem which Ofsted would prefer to blame on heads' and teachers' lack of curricular understanding. Other problems have been apparent since the start of Gove's hands-on redesign of the National Curriculum, including a failure to consider the pace of child development, an overemphasis on rules, a distaste for practical activity and the creative arts, and no consideration of learners' interests and concerns. These problems are not simply technical but reflect, to various degrees, the ideological baggage of the former Secretary of State. (See Wrigley 2014 for a more detailed analysis.)

The need for reform is pressing, but this cannot be done on the ad hoc and unprincipled basis suggested in the new Ofsted framework and handbooks. The starting point for any discussion of curriculum must be a reflection on educational aims, not only in general terms but for a particular place and time. Curriculum is inevitably a selection, and there is no sense in an unquestioning transmission of a body of knowledge down the decades. Further, as Raymond Williams (1965:6776) argued, the 'selective tradition' is partly shaped by the ideologies and demands of the ruling class.

It is also insufficient to assume employability as the first principle. Whilst education is key to a society's future capacity to provide for itself in material and economic ways, we have to understand economy in a very broad and collective sense, including caring for children and the old as paid and unpaid work, not simply to boost commercial profits or individual prospects (Mazzucato 2018). Beyond this, education should also prepare for participation in citizenship, culture, society.

These two fundamental errors of traditionalism and economism - indeed the conflicts and compromises between them - have underpinned several decades of state control of the school curriculum. On the one hand we have a neo-conservative traditionalism which, in the English context, draws upon early 20th Century grammar school curriculum as its authority. On the other we have a ruthless neo-liberal transformation of education into a mechanism to boost corporate profitability combined with individual social mobility for a few - education seen almost exclusively as the production of human resources (Ball 2008). The tension between neo-conservative and neoliberal aims shaped the original National Curriculum: on the one hand a traditionalist selection of cultural and social knowledge, with no opportunity to understand contemporary political issues, and 
on the other an unprecedented emphasis on economic modernisation through what is now called STEM (Design and Technology, ICT, double science for all) (Wrigley 2014).

Both these principles have continued to shape the English national curriculum, although the balance has shifted in line with government ideology. A prime example is New Labour's introduction of vocational diplomas from age 14 for roughly half the school population; pupils deemed 'non academic' (i.e. unlikely to enter university) were explicitly denied the entitlement to study history or geography, a foreign language, creative arts or design and technology. Conversely, Gove's neoconservative beliefs resulted in a push for grammatical knowledge, a traditional English literary canon, British history and 'knowledge' seen as memorisation of lists of facts (Wrigley 2014). The so-called EBacc, and performance measures such as Progress 8, have marginalised all practical or vocational studies and even the creative and performing arts.

It is important to realise that other curricular ideologies and models are available, both theoretically and practically. We are not limited to the above game. Indeed, we must look beyond the neoconservative / neoliberal binary at this time of potential curriculum renewal. What the neoconservative and neo-liberal ideologies have in common is that both believe in fitting individuals into a fixed society, not enabling them to become active in shaping the future. One alternative is the kind of progressivism which gives space and time for individuals to develop in their own way and learn to be kind and considerate to one another in face-to-face relationships. This process is fundamental to any humane form of childhood and adolescent education, and stands in strong contrast to the uncaring instrumentalism of the current accountability-driven system.

By itself however it remains inadequate. It has too narrow a view of 'care' limited to local interpersonal relations, and does not extend to caring on a wider scale, including for disadvantaged sections of society and the planet we depend on. A socially responsible and socially critical curriculum would go beyond this: it would be far more conscious of political power and social divisions, and of the need for young people to engage in collective movements for social change. It would empower young people to question and challenge unjust social structures and values, and indeed encourage direct social engagement during the years of schooling rather than deferred until adulthood (see Kemmis et al 1983 and Wrigley 2014:15-18 for further discussion).

It is particularly timely to discuss this question of curricular orientation at a time when so many young people have become alienated by their processing as 'human capital', and because their future requires not only technological innovation but environmental responsibility and democratic citizenship. This is precisely what Ofsted's much vaunted curriculum review has sidestepped. Ofsted's recently issued Inspection Handbook (2019:43) sees curriculum mainly as 'the knowledge and cultural capital they need to succeed in life'. It fails to recognise the importance of respect for 
the heritage of cultural minorities, or the need to provide young people living in poverty with an understanding of what causes poverty and how it can be resisted. It simply does not question whether schools should shape young people as cogs in a machine or alternatively develop their agency to challenge environmental degradation, inequality, prejudice and injustice.

\section{A curriculum to live and grow in}

The neoliberal push to intensify education as producer of 'human capital' has imposed unrealistic targets on learners, treating children like caged hens and creating massive emotional stress. As previously argued:

Rather than improving quality, it has led to greater superficiality. The spaces for more expansive and thoughtful learning have been taken over by the secretarial aspects of literacy, the explicit teaching of grammatical terminology, and rapid and accurate performance of arithmetic algorithms. (Wrigley 2018:183-4)

It has positioned very large numbers of children as failures. Around a third (and a half of children with free meal entitlement) are declared 'not secondary school ready' at age 11 . The hurdles have also been raised at age 16 through a new grading system and the so-called EBacc. In both primary and secondary school, important areas of curriculum have been eliminated or marginalised: spoken language, creative and performing arts, design and technology, education for citizenship. The curriculum has been disconnected from children's and young people's lives.

There are further dimensions of this disconnection, some of them socially selective. The lives, work and culture of working class communities has been eclipsed in the curriculum - reflecting a wider economic and cultural marginalisation. Brecht's lines crystallise this:

\section{Questions from a Worker who Reads}

... Caesar beat the Gauls.

Did he not even have a cook with him?

Without indulging in nostalgia, it is valuable to reflect on some of the pathways trodden in the 1960s to early 1980s, when the introduction of comprehensive schools provided a stimulus to a more inclusive curriculum: a period when history teachers began to engage with local working-class history, when English teachers built bridges between novels written for adolescents and literary texts, when autobiographical and other personal writing was considered worthwhile in itself but also as a pathway towards more formal genres. Creative and performing arts, sadly marginalised by SATs pressures and the EBacc, are a prime curricular space where young people can explore their identity and heritage, and experiment with possible futures. 
The creative arts curriculum, but also pedagogies such as dramatic improvisation and personal writing applied to other subjects, involve modes of learning which are both embodied and reflective / critical. Such pedagogies involve a movement between rich experience and abstract concepts. It is a serious weakness of the 'knowledge-based' curriculum favoured by Conservative politicians that experience is regarded as worthless and the accumulation of dead facts is seen as sufficient.

Connectedness and rootedness belongs to an extensive curricular and pedagogical tradition, dating back to Dewey, Pestalozzi (learning by 'head, heart and hand') and earlier. Jerome Bruner (1968) wrote of two equally important 'ways of knowing', the logico-scientific and the narrative modes, arguing that stories have their own way of explaining the world. Learners need the facility to move between these two modes, building concepts on retellings of experience but also testing out more abstract formulations through remembered and simulated events.

It seems to me that schools need to seek out two kinds of field to give a greater sense of reality to learning. One is to go out into the real world - fieldwork, placements, surveys etc. - and the other is various kinds of 'play' or 'imagined worlds'. Play, in this extended sense, can be applied at all stages of education, and provides the possibility of open exploration of possibilities, trytesting out options for change. Wartofsky (1973:208-9) wrote about rich forms of modelling including artistic representation (drama, novels) and simulations which have a special role in learning. For all their apparent realism, he recognised the particular value of them being 'off-line', i.e. a free space separate from the real world, without the constraints of economic reality. Because they are not reality itself, these spaces provide opportunities for experimentation, for playing out a range of possibilities not directly encountered within the constraints of real life. This aligns well with the notion of play outlined by Vygotsky (1978:92-104).

Such simulated realities enable learners to move comfortably between abstract representation and lived experience. They also allow for the possibility of stepping back out of role during a 'debriefing' stage, to discuss what has occurred at a meta-level, using more abstract language. An increasingly popular version of 'imagined world' pedagogies can be seen in Mantle of the Expert, a drama-based approach devised by Dorothy Heathcote and currently practised by Debra Kidd, Hywel Roberts, Tim Taylor and others.

In place of these rich connections, unless they have enlightened teachers who know how to work against the grain of official policy, children and young people are being offered a dessicated form of learning which is both age-inappropriate and socially and culturally remote. Of late, this has been justified by appeals to the value of 'knowledge' but that term is being used in restricted ways, limited either to lists of dry facts or to academic disciplines which distance themselves from everyday experience and understanding (see Wrigley 2018:186-91). 


\section{A richer sense of Knowledge}

Rather than build rich connections between the learners' experience and culture and established academic knowledge, Michael Young makes a virtue out of that divorce:

If education is to be emancipatory... it has to be based on a break with experience... The curriculum should exclude the everyday knowledge of students. (Young et al 2014: 88 and 97; see also discussion in Wrigley 2017)

Insisting on this separation simply reinforces:

standard educational processes whereby working-class culture is excluded and misrecognized, where Indigenous knowledges are denied, where cultural differences are elided and only professional and higher class cultures and knowledges are ratified and become cultural, social and symbolic capital that advantages some and disadvantages others.

(Wrigley et al 2012:198)

Emancipatory learning needs both to be rooted in popular experience and to give access to highstatus knowledge. Young people's development is richer and more authentic when cognitive developmented is grounded in experience and activity:

Such environments produce high-quality cognitive developmemnt, education for citizenship, and authentic engagement and motivation - knowledge that is more than a drizzle of inert facts and mind-numbing worksheets. They produce learning which is simultaneously grounded and critical. (Wrigley, Thomson and Lingard 2012:197)

There is no virtue in 'knowledge' which is decontextualised, fragmented, bleached of ethical and aesthetic political resonance: this is certainly not 'powerful knowledge' whether for understanding the natural world or gaining a critical understanding of society. We have much to learn from some of the educational pioneers of earlier decades, exemplified not least by attitudes to language. Harold Rosen and his colleagues rebelled against a tradition which believed that other forms of language than Standard English should be 'cured, cleansed, purged of deformities rather than extended, enriched, developed' (Rosen 1981:75). Their great lesson for us now is the importance of:

affirming the worth of the ordinary experience of working-class children and signifying it through improvised drama, classroom discussion and literary and argumentative writing. (Medway and Kingwell 2010:764)

English became a space in the curriculum which the lives of working-class students, their families and communities, were allowed to enter. But although the curriculum began in the local streets, it didn't end as a naive celebration of the here and now. English was a curriculum subject where 
students' critical and creative capacities were strongly developed. There is no contradiction between a sense of place and opening new horizons.

This is entirely in the spirit of Paulo Freire's 'education for liberation' and 'pedagogy of the oppressed' (1972), or more recent community-oriented educators such as Moll and Greenberg (1990) who have found ways of building on the 'funds of knowledge' of cultural minorities. Other recent pioneers include Nell Noddings (2006), whose book Critical Lessons builds an intellectually challenging and socially critical curriculum upon such themes as making a living, parenting and militarism; or Eric 'Rico' Gutstein (2006) whose 'citizenship mathematics' connects maths to students' pressing concerns.

Learning should entail a dialectical relationship between knowledge of past and present events and situations and the learners' own life experiences. Personal and community experiences can illuminate more formal knowledge, by enabling them to integrate it into their own understanding and empower their thoughts and actions.

\section{Building a broad, balanced, emancipatory curriculum}

It is now widely recognised that the curriculum has suffered from narrowness, and that we need to restore breadth and balance. Unfortunately this awareness does not go deep enough for Ofsted even to consider that a Key Stage 1 should go further than basic skills for later use ('ensuring that pupils are able to read, write and use mathematical knowledge, ideas and operations') or to think beyond EBacc for breadth and balance at Key Stage 4 (Ofsted 2019:43). The agency's notorious paper Bold Beginnings (2017) places almost exclusive emphasis on formal literacy and numeracy, whilst marginalising co-operation, self direction, play and even spoken language.

Ofsted are working with an impoverished understanding of knowledge and curriculum. Although the new School Inspection Handbook (Section 5) (Ofsted 2019:44) warns against 'simply memorising facts' rather than 'developing understanding', there is no recognition of the affective, ethical, political or aesthetic dimensions of knowledge or human development. Ironically, some thought has been given to a more extended sense of curriculum but it has been relegated to a separate section, Personal Development (p58seq). Inspectors are steered towards extracurricular activities (eg 'the Duke of Edinburgh award scheme, Cadet Forces and the National Citizenship Service') (p58). Within the curriculum, the place for personal development is 'citizenship, RE and other areas such as personal, social, health and economic education, and relationship and sex education' (p61). However so-called 'British values' are to be promoted 'through the curriculum, 
assemblies, visits, discussions and literature' and something called 'character' is to be built 'through the education that they [leaders] provide' (p61).

Whether under the heading Quality of Education, or that of Personal Development, there has been no attempt to reflect on the political significance of a curriculum which systematically neglects voice and agency - symbolised by removing recognition of spoken English, including at GCSE; by marginalising the arts; by providing no incentive for active investigation of real-world issues. Such pedagogical practices as project method, storyline, enquiry, prominent in many other education systems, have almost disappeared in England. There is no consideration of the need to gain active experiences of political engagement or environmental action.

It is important to assert a richer set of meanings of "broad and balanced" at this time.

a) It should insist on all learners, at least to the age of 16, gaining a deeper understanding of the natural world (through science) and society and the environment (through history, geography, elements of social sciences), and participating in creative and performing arts including digital media to enrich their capacity for self-expression.

b) Curriculum design should have an eye to students' all-round development as human beings physical, mental, cultural, ethical.

c) There should be an appropriate emphasis on practical studies, including some technical or vocational learning for all young people from age 14 . This should not be seen as an alternative curriculum for the 'less able', but recognise the importance of practical skills and experience in many different kinds of work. The practical strand of the curriculum should also give scope for innovation and creativity, as with the Design and Technology model.

d) Breadth and balance must be interpreted in terms of the developmental stage of the learner. We should not attempt to impose artificial targets on young children but aim to lay solid foundations. The curriculum must recognise that children develop at different speeds and with varying strengths, and that young children need a relatively informal learning environment with time for various kinds of play, construction, talk and interaction. Similarly, secondary education is more than exam preparation, and must remain open for students' ideas, initiatives and concerns.

e) The curriculum must reach across diverse forms of communication and expression, drawing on our rich cultural heritage: spoken and written language, mathematical symbols, graphic representations (maps, graphs, visual arts), music and embodied forms of expression (drama, dance), as well as electronic media. Language development should embrace foreign and community languages and dialects as well as Standard English. 
f) Young people should be introduced to a range of different forms of enquiry, whether scientific experiment and historical interpretation or pedagogical approaches such as project-based learning and dramatic simulations. ADD at all stages their voice and agency should be encouraged, and opportunities provided for performance and presentation of their thinking to others.

g) Experiential differences relating to class, gender and ethnicity should be acknowledged and learning enriched by these different perspectives. Questions of social justice must run through the curriculum.

h) Environmental and political concerns form the basis for education in democratic citizenship. Young people need to engage with issues and develop critical capacities, including the scope to plan and engage in appropriate forms of social initiative. There needs to be space for students to pursue their own pressing concerns.

i) Schools and localities should have the scope to develop the curriculum in detail in response to their particular circumstances, within a broad national framework and in consultation with students, parents and community groups. The National Curriculum should not be overloaded with detail, and assessment should reflect the intended breadth, balance and emancipatory aims.

This richer understanding of 'broad and balanced' responds to a socially just and emancipatory orientation to curriculum - the only fitting orientation for a new kind of public school enabled by a National Education Service. This is not to deny economic needs, whether individual or collective. Indeed, a curriculum infused with these principles and values will provide all young people with the knowledge and skills and attitudes to make their way in the world, and produce a creative and responsible population which can move beyond our current economic stagnation. Education for liberation does not deny economic realities, in the broadest sense of the word, nor does it deprive young people of a rich heritage of knowledge and culture ('the best that has been thought and said', indeed). Rather it enables students to draw on theory and culture to illuminate the complex and worrying realities of the world they inhabit, and find new ways of building a better, more sustainable future.

\section{References}

Ball, S (2008) The education debate. Bristol: Policy Press

Bruner, J (1968) Two modes of thought. In Actual minds, possible worlds. Cambridge MA: Harvard University Press

Freire, P (1972) Pedagogy of the oppressed. Harmondsworth: Penguin 
Gutstein, E (200) Reading and writing the world with mathematics: towards a pedagogy for social justice. London: Routledge

Kemmis, S, Cole, P and Suggett, D (1983) Orientations to curriculum and transition: towards the socially critical school. Melbourne: Victorian Institute of Secondary Education https://files.eric.ed.gov/fulltext/ED295339.pdf

Mazzucato, M (2018) The value of everything: making and taking in the global economy. Penguin

Medway, P and Kingwell, P (2010) A curriculum in its place: English teaching in one school 1946-1963. History of Education 39(6), 749-65

Moll, L and Greenberg, J (1990) Creating zones of possibilities: combining social contexts for instruction. In L Moll (ed) Vygotsky and education. Cambridge MA: Harvard University Press

Noddings, N (2006) Critical lessons: what our schools should teach. Cambridge: Cambridge University Press

Ofsted (2017) Bold beginnings: the Reception curriculum in a sample of good and outstanding primary schools (Nov 2017, no. 170045).

Ofsted (2019) School inspection handbook (Section 5) (May 2019)

Rosen, H (1981) Neither Bleak House nor Liberty Hall: English in the curriculum. In J Richmond (ed) (2017) Harold Rosen: Writings on life, language and learning 1958-2008. London: UCL IOE Press

Vygotsky, L (1978) The role of play in development, in Vygotsky: Mind in society: the development of higher psychological processes. Cambridge MA: Harvard University Press

Wartofsky, M (1973) Models. Dordrecht: D Reide

Williams, R (1965) The Long Revolution. Harmondsworth: Penguin

Wrigley, T, Thomson, P and Lingard, B (2012) Resources for changing schools: ideas in and for practice. In $\mathrm{T}$ Wrigley, $\mathrm{P}$ Thomson and B Lingard (eds) Changing schools: alternative ways to make a world of difference. London: Routledge

Wrigley, T (2014) The politics of curriculum in schools. London: Centre for Labour and Social Studies (CLASS). www.classonline.org.uk

Wrigley, T (2017) Canonical knowledge and common culture(s): in search of curricular justice. European Journal of Curriculum Studies.

Wrigley, T (2018) For the many: a curriculum for social justice. FORUM 60(2), pp179-195

Young, M, and Lambert, D, with Roberts, C and Roberts M (2014) Knowledge and the future school: curriculum and social justice. London: Bloomsbury

TERRY WRIGLEY is Visiting Research Fellow at Manchester Metropolitan University and editor of the journal Improving Schools. His books include Living on the Edge (with John Smyth) and Changing Schools (co-edited with Bob Lingard and Pat Thomson). Terry is keenly interested in schools policy, curriculum and social justice, and helps coordinate the Reclaiming Schools researchers' network

(www.reclaimingschools.org). Correspondence: terrywrigley@gmail.com 